\title{
SCIENTIFIC REPORTS

\section{OPEN Introducing national osteopathy practice-based research networks in Australia and New Zealand: an overview to inform future osteopathic research}

\begin{abstract}
Amie Steel $\mathbb{1}^{*}$, Wenbo Peng, David Sibbritt \& Jon Adams
Both the Osteopathic Research Innovation Network (ORION) and the Osteopathy Research ConnectNew Zealand (ORC-NZ) are practice-based research networks (PBRNs) recently established in Australia and New Zealand. This paper highlights the profile of the osteopaths participating in each PBRN in order to encourage and facilitate further related research in osteopathy. All registered osteopaths in Australia and New Zealand were invited to participate in the ORION and ORC-NZ PBRNs, respectively. This paper presents practice and sociodemographic characteristics of the osteopaths that elected to join the PBRN in their country. A total of 253 registered osteopaths in New Zealand (48.7\%) agreed to join ORC-NZ while 992 registered osteopaths in Australia (44.5\%) joined ORION. Membership of both PBRNs reflect national geographical spread, and diverse personal and practice characteristics. Combined membership of both PBRNs represents $45.3 \%$ of all registered osteopaths in Australasia and $7.7 \%$ of the global osteopathic profession. The PBRNs, independently and in combination, hold much potential to advance the evidence-base and capacity of osteopathy research. Both ORION and ORC-NZ PBRNs are powerful, innovative resources available to other interested parties to help conduct further osteopathy research in Australia and New Zealand.
\end{abstract}

Osteopathy - a manual therapy which follows the principle that structure and function are closely integrated by assessing a person's musculoskeletal, neurological and visceral systems ${ }^{1}$ - is currently practiced in more than 50 countries worldwide ${ }^{1}$ with a substantial user cohort ${ }^{2}$ especially amongst those seeking care for back pain $(8.8 \%)^{3}$. In both Australia and New Zealand, osteopathy is an integrated registered health profession ${ }^{4}$, and there is equivalence in the educational requirements to practice osteopathy in accordance with a Trans-Tasman Mutual Recognition Agreement between the professional bodies in both countries ${ }^{5,6}$. Combined, the Australian and New Zealand osteopathic professions represent $17 \%$ of the global profession ${ }^{4}$. This is the third highest proportional number of osteopaths, succeeded only by the United States (24.6\%) and France (28.9\%)

Despite the widespread practice and use of osteopathy, there remain substantial gaps in the evidence required to best situate osteopathy within contemporary health systems around the world. The quantity and quality of osteopathic research has advanced in recent years and includes pockets of a variety of research interests with particular foci on applied physiology and education ${ }^{7}$. While some research has also investigated specific osteopathic manipulative treatments $s^{8-19}$, much of this efficacy research has occurred outside of an osteopathic clinical setting. For example, a recent review of osteopathic manipulative treatments found only nine whole systems comparative effectiveness studies investigating the outcomes of osteopathic care within a real-world practice environment ${ }^{20}$. Yet, osteopathic treatment is argued to encompass practice and philosophical characteristics that extend beyond osteopathic manipulative treatment alone ${ }^{21}$. There is also range of topics beyond clinical efficacy that relate to the practice and provision of osteopathic care in the community requiring researcher attention, including: a better understanding of the use and users of osteopathy; an exploration of the practice and practices of osteopaths; the positioning of osteopaths alongside other health professionals within different health systems; and the place of 


\begin{tabular}{|c|c|c|c|c|c|}
\hline Name & $\begin{array}{l}\text { Geographical } \\
\text { coverage }\end{array}$ & $\begin{array}{l}\text { AHRQ } \\
\text { registration* }\end{array}$ & $\begin{array}{l}\text { Membership/ } \\
\text { specialty }\end{array}$ & Size** & Funding \\
\hline ACORN & $\begin{array}{l}\text { National/ } \\
\text { Australia }\end{array}$ & Yes & Chiropractors & $>1680$ & $\begin{array}{l}\text { Chiropractors' } \\
\text { organization of } \\
\text { Australia }\end{array}$ \\
\hline $\begin{array}{l}\text { CONCORD } \\
\text { PBRN }\end{array}$ & $\begin{array}{l}\text { National/ } \\
\text { US }\end{array}$ & Yes & Osteopaths & $>20$ & $\begin{array}{l}\text { Osteopathic } \\
\text { Research Centre } \\
\text { at Texas College } \\
\text { of Osteopathic } \\
\text { Medicine }\end{array}$ \\
\hline CSRN & $\begin{array}{l}\text { International/ } \\
\text { US-based }\end{array}$ & Yes & $\begin{array}{l}\text { Chiropractic } \\
\text { scoliosis specialists }\end{array}$ & $\begin{array}{l}>50 \\
\text { centres }\end{array}$ & $\begin{array}{l}\text { CLEAR scoliosis } \\
\text { institute }\end{array}$ \\
\hline $\begin{array}{l}\text { DO- } \\
\text { Touch.NET }\end{array}$ & $\begin{array}{l}\text { National/ } \\
\text { US }\end{array}$ & Yes & Osteopaths & 159 & $\begin{array}{l}\text { A.T. Still } \\
\text { University }\end{array}$ \\
\hline $\begin{array}{l}\text { ICON/ } \\
\text { unnamed } \\
\text { PBRN }\end{array}$ & $\begin{array}{l}\text { National/ } \\
\text { US }\end{array}$ & No & Chiropractors & NA & NA \\
\hline ICPA PBRN & $\begin{array}{l}\text { International/ } \\
\text { US-based }\end{array}$ & Yes & $\begin{array}{l}\text { Chiropractors/ } \\
\text { paediatrics }\end{array}$ & 3500 & ICPA \\
\hline PRACI & $\begin{array}{l}\text { National/ } \\
\text { Australia }\end{array}$ & Yes & $\begin{array}{l}\text { Complementary } \\
\text { medicine } \\
\text { practitioners } \\
\text { including manual } \\
\text { therapists }\end{array}$ & $\begin{array}{l}>1000 \\
(\sim 700 \\
\text { manual } \\
\text { therapists) }\end{array}$ & $\begin{array}{l}\text { Endeavour } \\
\text { College of Natural } \\
\text { Health }\end{array}$ \\
\hline
\end{tabular}

Figure 1. Summary of Manual Therapy Practice-based Research Networks Globally [source: Lee et al. ${ }^{28}$ ]. ACORN, Australian Chiropractic Research Network; AHRQ, Agency for Healthcare Research and Quality; BraveNet, Bravewell Integrative Medicine Research Network; CAM, complementary and alternative medicine; CONCORD, Consortium for Collaborative Osteopathic Research Development; CSRN, CLEAR (Chiropractic, Leadership, Educational, Advancement and Research) Scoliosis Research Network; DO-Touch.NET, Doctors of Osteopathy Treating with Osteopathic Manipulative Medicine: determining its Usefulness in Current Healthcare; ICPA, International Chiropractic Pediatric Association; IM, integrative medicine; NA, not available; PBRN, practice-based research network.

osteopathic care within diverse health policy environments ${ }^{7}$. Further infrastructure is needed to build upon the resources and capacity currently available in both Australia and New Zealand to effectively support the breadth and scale of research required to address these and other research topics ${ }^{22,23}$.

A practice-based research network (PBRN) design providing research infrastructure and capacity -building has grown in popularity globally over the last 20 years ${ }^{24,25}$. A PBRN is a group of at least 15 ambulatory practices and/or 15 clinicians that affiliate together and collaborate with academic institutions for conducting research ${ }^{26,27}$. The organisational structure of a PBRN extends beyond any one single study and often encompasses administrative and managerial staff who work alongside the academic contributors and practitioner members to fulfil a shared mission and purpose in research ${ }^{26}$.

Internationally, a number of PBRNs have been established which encompass clinicians from manual therapy professions (see Fig. 1) ${ }^{28}$. Two of these are national PBRNs of osteopaths in the US; the Consortium for Collaborative Osteopathic Research and Development (CONCORD) coordinated from the Texas College of Osteopathic Medicine ( $\mathrm{n}>20)$ and the Doctors of Osteopathy Treating with Osteopathic manipulative medicine (DO-Touch.NET) managed by A.T. Still University $(n=159)^{28}$. There are also four other PBRNs in Australia that focus upon or include focus upon manual therapists: the Australian Chiropractic Research Network (ACORN) with over 1,680 members ${ }^{29}$; the Practitioner Research and Collaboration Initiative (PRACI) including more than 700 clinicians from a range of manual therapy professions (massage therapy, kinesiology, bowen therapy, myotherapy, and reflexology) alongside other complementary medicine practitioners (over 1,000 members in total) ${ }^{30}$; the Osteopathy Research and Innovation Network (ORION) in Australia and Osteopathy Research Connect-New Zealand (ORC-NZ) in New Zealand. These latter two PBRNs, exclusively focused upon osteopathy and recently established, are overviewed in this paper with a view to helping inform all possible parties of the potential for further collaborations and opportunities to examine a vast range of osteopathy-related issues directly drawing upon these two PBRN initiatives.

\section{Methodology}

Study objectives. This paper aims to describe the characteristics of the members of two osteopathy practice-based research networks (PBRNs); the ORION PBRN established in Australia and the ORC-NZ PBRN established in New Zealand. While these two PBRNs were established and developed separately, they were designed in part by a common group of senior health researchers and we here provide this description of the projects with a view to helping illustrate how these two PBRNs, both independently but also collectively, constitute significant research infrastructure open to others who wish to answer any of a vast number of osteopathy-related or osteopathy-specific research questions. 
Setting. Recruitment dates differed for each PBRN with ORION recruitment occurring between July 2016 and June 2017 and ORC-NZ recruiting between August and December 2018. Prior to each recruitment period, the research team engaged in each location for up to 12 months to promote to and inform the osteopathic community in each country regarding the forthcoming PBRNs.

Participants. For both PBRNs, all registered osteopaths in the respective country were invited to participate. Recruitment in Australia was primarily conducted through Osteopathy Australia (OA), the leading professional association for osteopaths. At the time of recruitment there were 1,800 members in OA which represented $80.7 \%$ of the 2,230 registered osteopaths in Australia. ORC-NZ recruitment was conducted primarily via the national osteopathy association, Osteopaths New Zealand which had 300 members at the time of recruitment $(57.8 \%$ of the total 519 registered osteopaths at this time). In addition, the Osteopathic Council of New Zealand, the national registration board for osteopaths, also disseminated invitations to all New Zealand-registered osteopaths regarding participating in the ORC-NZ PBRN.

Instrument. Data for both PBRNs were collected via an online self-reported questionnaire. The questionnaire was designed with the input from several registered osteopaths in each country - including both professional leaders and those in full-time clinical practice - to ensure face validity. The questionnaire used in each country was matched except for items unique to the local context of each country (e.g. reimbursement models, location of clinical practice). The final instrument included items across three domains: practitioner characteristics, clinical practice characteristics, and clinical management.

Practitioner characteristics. Both groups of respondents in Australia and New Zealand were asked to provide details of their age, gender, highest level of osteopathic qualification, professional association membership, and professional roles (e.g. university teaching, clinical supervision, private practice). ORC-NZ respondents were also invited to identify the country they completed their first osteopathic qualification.

Clinical practice characteristics. Both questionnaires collected details about the average number of patient care hours and patient visits per week, practice location/s, co-location and referrals with other health professionals, use of imaging and other diagnostic techniques, and use of electronic records and record-keeping software in clinical practice.

Clinical management. Both surveys included items that asked participants about: the public health/health promotion topics (e.g. diet/nutrition, smoking/drugs/alcohol, physical activity/fitness) they discussed with patients as part of their care/management plans; the frequency with which the osteopath treated patients with specific health conditions (e.g. neck pain, low back pain, postural disorders); the frequency with which the osteopath treated different patient subgroups (e.g. children, pregnant women, ethnic populations); and the osteopath's use of specific techniques/methods (e.g. peripheral joint manipulation, myofascial release, spinal manipulation). All survey items for both projects related to frequency included scaled response items (never, rarely, sometimes, often)

After completing the respective survey, participants were invited to provide consent to join the relevant PBRN. This consent included permission for their responses to be identifiably linked to their contact information as part of the respective PBRN database. Those participants who gave such consent provided their first and last name, contact address, email and phone number.

Statistical analysis. Categorical variables are reported descriptively as frequencies and percentages and continuous variables are reported as a mean with standard deviation. Both cohorts were assessed for representativeness using chi square goodness of fit tests using the data provided through reports from the Osteopathy Board of Australia (for ORION) and Osteopathic Council of New Zealand (for ORC-NZ). All statistical analysis was performed using Stata 14.1 Statistical Analysis software.

Ethical clearance. This research complies with international standards for ethical conduct as outlined by the Declaration of Helsinki. All participants provided informed consent to participate in the study. Approval for this study was granted by the Human Research Ethics Committee of the University of Technology Sydney.

\section{Results}

A total of 253 osteopaths in New Zealand completed the ORC-NZ survey and agreed to join the ORC-NZ PBRN, representing $48.7 \%$ of registered osteopaths in that country at the time of recruitment. The 992 osteopaths in Australia who completed the ORION survey and agreed to join the ORION PBRN represent 44.5\% of Australian registered osteopaths at the time of recruitment. Combined, both PBRN practitioner populations represent $45.3 \%$ of all registered osteopaths in Australasia.

The ORC-NZ PBRN members were predominantly male (53.0\%), had received their first osteopathic qualification in England (51.0\%) or New Zealand (39.9\%) and reported a Masters (47.2\%) or Bachelor (26.2\%) degree as their highest osteopathic qualification (see Table 1). Members were an average of 45.4 years old (mean) and reported having been in practice for 15.3 years (mean). Aside from clinical practice, the ORC-NZ PBRN members describe holding a range of other occupational roles including volunteer (18.2\%), professional organisation involvement (17.0\%) and clinical supervision (of associates [15.8\%] and students [7.5\%]). Most members described their practice location as 'urban' $(88.5 \%)$.

More ORION PBRN members were female (58.1\%) than male (41.9\%) with a mean age of 38.0 years old (see Table 1). The substantive majority had been awarded a Master degree as their highest osteopathic qualification (68.7\%) while $21.6 \%$ had a Bachelor degree. The ORION PBRN members reported being in practice for 11.4 


\begin{tabular}{|c|c|c|}
\hline \multirow[b]{2}{*}{ Practitioner characteristics } & ORC-NZ $(n=253)$ & ORION $(n=992)$ \\
\hline & n (\%)* & n (\%)* \\
\hline \multicolumn{3}{|l|}{ Gender } \\
\hline Female & $134(46.6)$ & $576(58.1)$ \\
\hline Male & $118(53.0)$ & $416(41.9)$ \\
\hline Other & $1(0.4)$ & 0 \\
\hline Age in years [mean $(\mathrm{SD})]^{*}$ & $45.4(12.0)$ & $38.0(10.9)$ \\
\hline \multicolumn{3}{|l|}{ Country qualified } \\
\hline England & $129(51.0)$ & - \\
\hline New Zealand & $101(39.9)$ & - \\
\hline Australia & $19(7.5)$ & - \\
\hline Other & $4(1.6)$ & - \\
\hline Years in practice $[\text { mean }(\mathrm{SD})]^{*}$ & $15.3(10.6)$ & $11.4(9.0)$ \\
\hline \multicolumn{3}{|l|}{ Highest osteopathic qualification } \\
\hline Diploma & $40(15.9)$ & - \\
\hline Advanced diploma & $2(0.8)$ & $9(0.9)$ \\
\hline Bachelor (or Double Bachelor) degree & $66(26.2)$ & $214(21.6)$ \\
\hline Postgraduate certificate or diploma & $17(6.8)$ & $61(6.2)$ \\
\hline Masters degree & $119(47.2)$ & $681(68.7)$ \\
\hline Other (includes PhD) & $8(3.2)$ & $27(2.7)$ \\
\hline \multicolumn{3}{|l|}{ Occupational role } \\
\hline University or other teaching & $23(9.1)$ & $116(11.7)$ \\
\hline Clinical supervision of students & $19(7.5)$ & \multirow{2}{*}{$150(15.1)$} \\
\hline Clinical supervision of associates & $40(15.8)$ & \\
\hline Professional organisation involvement & $43(17.0)$ & $107(10.8)$ \\
\hline Research & $19(7.5)$ & $54(5.4)$ \\
\hline Volunteer & $46(18.2)$ & $159(16.0)$ \\
\hline \multicolumn{3}{|l|}{ Regionality of primary practice } \\
\hline Urban & $224(88.5)$ & $820(82.7)$ \\
\hline Rural & $59(22.1)$ & $212(21.4)$ \\
\hline Remote & $4(1.6)$ & $11(1.1)$ \\
\hline
\end{tabular}

Table 1. Characteristics of members of ORC-NZ $(n=253)$ and ORION $(n=992)$. *Figures are presented as frequencies and percentages except for continuous variables which are presented as mean and standard deviation.

years (mean) although they also undertook other occupational roles; primarily, volunteer (16.0\%) and/or clinical supervision (15.1\%). Most members reported practicing in an urban location (82.7\%).

As seen in Table 2, the majority of ORC-NZ PBRN members indicated their primary practice as located in Auckland (29.6\%) while the least number described Northland (4.4\%) or Manawatu (4.4\%) as their location of practice. ORION members most commonly reported having their primary practice located in Victoria $(56.4 \%)$, New South Wales (26.5\%) or Queensland (9.0\%). Northern Territory (0.2\%), Australian Capital Territory (1.7\%) and South Australian (1.8\%) were reported least frequently.

Table 3 describes the clinical practice characteristics of both members of both PBRNs. Members of the ORC-NZ PBRN reported 32.3 patient visits (mean) over 27.5 hours (mean) per week. The majority of ORC-NZ PBRN members practiced in only one clinical location (66.8\%) and shared their clinical location with other health professionals (69.8\%). Osteopaths were the most common type of health professional co-located with ORC-NZ PBRN members, followed by massage therapists (45.2\%) and acupuncturists (38.4\%). Most commonly, members of ORC-NZ reported sending referrals to general practitioners (GPs) (90.3\%), specialist doctors (76.6\%) and acupuncturists (71.4\%). Referrals were also received from GPs (92.1\%) as well as osteopaths (78.3\%) and massage therapists (77.1\%). Meanwhile, ORION PBRN members reported consulting with 37.0 (mean) patients over an average of 28.2 (mean) practice hours per week. The majority of ORION PBRN members reported practicing from one clinical location (65.0\%), co-located with at least one other osteopath (64.8\%), although it was common for a massage therapist (50.5\%) to also share the practice site of these osteopaths. GPs $(88.5 \%)$, podiatrists $(65.6 \%)$ and massage therapists $(67.6 \%)$ were sent referrals from ORION PBRN members most frequently, while receiving referrals from GPs (89.3\%), massage therapists (76.0\%) and/or osteopaths (61.9\%) was also reported amongst the ORION PBRN members.

Table 4 reports clinical management practices regarding diagnostic techniques and record-keeping by members of both PBRNs. ORC-NZ PBRN members employed diagnostic imaging 'sometimes' (65.2\%) or 'often' (22.9\%) in their clinical care and the most common clinical assessment techniques employed by these NZ osteopaths were orthopaedic testing (96.8\%), neurological testing (95.3\%), screening questionnaire $(88.5 \%)$, and cranial neurological testing $(68.8 \%)$. Approximately more than half of all ORC-NZ PBRN members utilised 


\begin{tabular}{|c|c|c|c|}
\hline \multicolumn{2}{|c|}{ ORC-NZ $(n=253)$} & \multicolumn{2}{|l|}{ ORION $(\mathbf{n}=992) *$} \\
\hline Northland & $11(4.4)$ & Australian Capital Territory & $17(1.7 \%)$ \\
\hline Auckland & $75(29.6)$ & New South Wales & $263(26.5 \%)$ \\
\hline Bay of Plenty & $27(10.7)$ & Northern Territory & $2(0.2 \%)$ \\
\hline Waikato & $27(10.7)$ & Queensland & $89(9.0 \%)$ \\
\hline Manawatu & $11(4.4)$ & South Australia & $18(1.8 \%)$ \\
\hline Wellington & $30(11.9)$ & Tasmania & $22(2.2 \%)$ \\
\hline Nelson & $13(5.1)$ & Victoria & $559(56.4 \%)$ \\
\hline Canterbury & $24(9.5)$ & Western Australia & $32(3.2 \%)$ \\
\hline Otago & $15(5.9)$ & & \\
\hline Other regions & $25(9.9)$ & & \\
\hline
\end{tabular}

Table 2. Location of Primary Practice by Region or State of ORC-NZ $(n=253)$ and ORION $(n=992)$. *Participants could select more than one response and as such the sum of the reported frequencies is greater than $100 \%$.

electronic records for case file management including initial history (54.9\%), examination findings (54.6\%) and/ or subsequent patient visits (56.1\%). ORION PBRN members reported 'sometimes' (55.9\%) or 'rarely' (36.2\%) using diagnostic imaging in their clinical practice and these Australian-based osteopaths listed orthopaedic testing $(97.6 \%)$ and neurological testing $(92.5 \%)$ most frequently for clinical assessment, more so than cranial neurological testing $(67.7 \%)$ and screening questionnaires $(63.8 \%)$. Electronic records were reportedly utilised by approximately three quarters of all ORION PBRN members, including for initial history (73.2\%), examination findings (74.1\%), and/or subsequent patient visits (76.5\%).

The conditions and populations treated by members of both osteopathy PBRNs are presented in Table 5. Neck pain (98.4\%), low back pain (98.4\%), thoracic spine and rib pain (88.9\%), headache disorders (86.6\%) and shoulder musculoskeletal disorders were reported by the most ORC-NZ PBRN members as being treated 'often. While $47.3 \%$ of ORC-NZ PBRN members indicated they 'rarely' or 'never' treated non-musculoskeletal disorders, $36.5 \%$ 'sometimes' and $16.3 \%$ 'often' treated this category of condition. The most common populations treated by ORC-NZ PBRN members were older people (65 years and over) (66.4\%), people with work-related injuries (64.8\%) and people with sports-related injuries (51.8\%). Patients claiming Accident Compensation Corporation (ACC) reimbursement were also treated by the majority of ORC-NZ PBRN members $(88.1 \%)$. The majority of ORC-NZ PBRN members 'sometimes' treated patients identifying as Maori (55.7\%), pregnant women (53.0\%), and children between the ages of 4 and 18 years old (51.2\%). Younger children (up to 3 years old) were 'rarely' or 'never' treated by $40.8 \%$ of ORC-NZ PBRN members.

ORION PBRN members often treated low back pain (98.7\%), neck pain (98.0\%), thoracic spine and rib pain (91.7\%), headache disorders $(90.1 \%)$ and shoulder musculoskeletal disorders (81.0\%). Non-musculoskeletal disorders were 'never' or 'rarely' treated by $60.5 \%$ of ORION PBRN members. More than half of the ORION membership reported 'often' treating older people (65 years and over) (57.7\%) and people with sports-related injuries (50.6\%), and 'sometimes' treating children between the ages of 4 and 18 years old (55.0\%) and pregnant women (53.9\%). Australian indigenous people were 'rarely' (55.3\%) or 'never' (33.4\%) treated by ORION PBRN members, as were patients from non-English speaking ethnic groups (rarely: $46.2 \%$; never: $35.0 \%$ ) or children younger than three years old (rarely: $30.8 \%$; never: $31.5 \%$ ).

The most common topics discussed with patients as part of their care plan by ORC-NZ PBRN members were physical activity/fitness (86.9\%), stress management (53.8\%) and occupational health and safety (43.3\%) (see Table 6). Other topics such as smoking, drugs and alcohol (52.8\%), medications (51.8\%), nutritional supplements (47.4\%), and diet/nutrition (46.8\%) were 'sometimes' discussed by substantial numbers of ORC-NZ PBRN members. A range of techniques were reported by ORC-NZ PBRN members as employed in their treatment of patients, with the most common being soft issue techniques (87.4\%), exercise prescription or advice (78.3\%), high velocity-low amplitude/spinal manipulation $(61.3 \%)$, myofascial release $(60.9 \%)$, muscle energy techniques (59.9\%), peripheral joint manipulation (53.8\%) and cranial techniques (50.6\%). ORION PBRN members reported 'often' discussing physical activity/fitness (89.4\%) and occupational health and safety (51.2\%) with their patients. Other topics such as medications (48.0\%), diet/nutrition (47.0\%), smoking/drugs/alcohol (45.9\%) and nutritional supplements $(45.0 \%)$ were also 'sometimes' discussed with patients by ORION PBRN members. The most common techniques used by ORION PBRN members when treating patients were soft tissue techniques (85.7\%), muscle energy techniques (79.5\%), exercise prescription or advice (74.0\%), visceral techniques $(70.0 \%)$, high velocity-low amplitude/spinal manipulation (63.8\%) and myofascial release (61.8\%).

\section{Discussion}

This paper presents an overview of the practitioner and practice characteristics of those osteopaths who are foundational members of either the ORION PBRN or ORC-NZ PBRN with a view to encouraging and facilitating further research drawing upon each or both of the PBRN baseline membership databases. These two PBRN initiatives represent the two most extensive voluntary PBRNs in the world with regards to coverage of a health profession. Such recruitment success, exceeding the proportion of the chiropractic profession recruited to the ACORN PBRN in Australia $(36 \%)^{29}$, is built upon memberships of $48.7 \%$ and $45.3 \%$ of the total profession in New Zealand and Australia respectively. By establishing these osteopathy PBRNs (sharing a similar baseline instrument design 


\begin{tabular}{|c|c|c|}
\hline \multirow[b]{2}{*}{ Practice characteristics } & \multirow{2}{*}{$\begin{array}{l}\text { ORC-NZ }(\mathrm{n}=253) \\
\text { Mean }(\mathrm{SD})\end{array}$} & \multirow{2}{*}{\begin{tabular}{|l|} 
ORION $(\mathbf{n}=992)$ \\
Mean $(\mathrm{SD})$
\end{tabular}} \\
\hline & & \\
\hline Patient care hours & $27.5(11.1)$ & $28.2(11.8)$ \\
\hline \multirow[t]{2}{*}{ Patient visits } & $32.3(22.4)$ & $37.0(18.3)$ \\
\hline & n (\%) & n (\%) \\
\hline Practice in more than one location & $84(33.2)$ & $347(35.0)$ \\
\hline Practice with other health professionals & $185(69.8)$ & - \\
\hline Osteopath & $139(78.5)$ & $643(64.8)$ \\
\hline General practitioner & $17(9.6)$ & $72(7.3)$ \\
\hline Specialist doctor & $5(2.8)$ & $31(3.1)$ \\
\hline Podiatrist & $17(19.6)$ & $147(14.8)$ \\
\hline Physiotherapist & $34(19.2)$ & $144(14.5)$ \\
\hline Exercise physiologist & $4(2.3)$ & $124(12.5)$ \\
\hline Occupational therapist & $4(2.3)$ & $19(1.9)$ \\
\hline Psychologist & $34(19.2)$ & $191(19.3)$ \\
\hline Massage therapist & $80(45.2)$ & $501(50.5)$ \\
\hline Chiropractor & $10(5.7)$ & - \\
\hline Acupuncturist & $68(38.4)$ & $188(19.0)$ \\
\hline Naturopath & $29(16.4)$ & $193(19.5)$ \\
\hline Dietician & $6(3.4)$ & $72(7.3)$ \\
\hline Nutritionist & $18(10.2)$ & $78(7.9)$ \\
\hline \multicolumn{3}{|l|}{ Send referrals } \\
\hline Osteopath & $159(64.1)$ & $506(51.0)$ \\
\hline General practitioner & $224(90.3)$ & $878(88.5)$ \\
\hline Specialist doctor & $190(76.6)$ & $443(44.7)$ \\
\hline Podiatrist & $97(39.1)$ & $651(65.6)$ \\
\hline Physiotherapist & $113(45.6)$ & $331(33.4)$ \\
\hline Exercise physiologist & $20(8.1)$ & $398(40.1)$ \\
\hline Occupational therapist & $24(9.7)$ & $106(10.7)$ \\
\hline Psychologist & $82(33.1)$ & $349(35.2)$ \\
\hline Massage therapist & $160(64.5)$ & $671(67.6)$ \\
\hline Chiropractor & $18(7.3)$ & - \\
\hline Acupuncturist & $177(71.4)$ & $451(45.5)$ \\
\hline Naturopath & $105(42.3)$ & $477(48.1)$ \\
\hline Dietician & $19(7.7)$ & $167(16.8)$ \\
\hline Nutritionist & $49(19.8)$ & $129(13.0)$ \\
\hline \multicolumn{3}{|l|}{ Receive referrals } \\
\hline Osteopath & $188(78.3)$ & $614(61.9)$ \\
\hline General practitioner & $221(92.1)$ & $886(89.3)$ \\
\hline Specialist doctor & $79(32.9)$ & $237(23.9)$ \\
\hline Podiatrist & $49(20.4)$ & $471(47.5)$ \\
\hline Physiotherapist & $114(47.5)$ & $266(26.8)$ \\
\hline Exercise physiologist & $15(6.3)$ & $258(26.0)$ \\
\hline Occupational therapist & $22(9.2)$ & $61(6.1)$ \\
\hline Psychologist & $40(16.7)$ & $154(15.5)$ \\
\hline Massage therapist & $185(77.1)$ & $754(76.0)$ \\
\hline Chiropractor & $17(7.1)$ & - \\
\hline Acupuncturist & $129(53.8)$ & $370(37.3)$ \\
\hline Naturopath & $96(40.0)$ & $400(40.3)$ \\
\hline Dietician & $7(2.9)$ & $39(3.9)$ \\
\hline Nutritionist & $19(7.9)$ & $55(5.5)$ \\
\hline
\end{tabular}

Table 3. Clinical practice characteristics of members of ORC-NZ $(n=253)$ and ORION $(n=992)$.

contextualised to each local setting), the infrastructure of each PBRN capitalises on the Trans-Tasman Mutual Recognition in place between both countries ${ }^{5,6}$ and provides the opportunity for Australasian osteopathy research projects maximising the value of each individual PBRN. As the cumulative membership of the two PBRNs represents $7.7 \%$ of the global osteopathic profession ${ }^{1}$, these large scale program initiatives hold much potential to facilitate future osteopathy research. 


\begin{tabular}{|l|l|l|}
\hline \multicolumn{2}{|l|}{ ORC-NZ (n=253) } & ORION (n=992) \\
\hline Diagnostic imaging & $1(0.4)$ & $6(0.6)$ \\
\hline Never & $29(11.5)$ & $359(36.2)$ \\
\hline Rarely & $165(65.2)$ & $554(55.9)$ \\
\hline Sometimes & $58(22.9)$ & $73(7.4)$ \\
\hline Often & $245(96.8)$ & $968(97.6)$ \\
\hline Clinical assessment techniques & $77(30.4)$ & $468(47.2)$ \\
\hline Orthopaedic testing & $241(95.3)$ & $918(92.5)$ \\
\hline Clinical assessment algorithm & $224(88.5)$ & $633(63.8)$ \\
\hline Neurological testing & $174(68.8)$ & $672(67.7)$ \\
\hline Screening questionnaire & \multicolumn{2}{|l|}{} \\
\hline Cranial neurological testing & $139(54.9)$ & $726(73.2)$ \\
\hline Electronic records & $138(54.6)$ & $735(74.1)$ \\
\hline Initial history & $142(56.1)$ & $759(76.5)$ \\
\hline Examination findings & $110(43.5)$ & $232(23.4)$ \\
\hline Subsequent patient visits & &
\end{tabular}

Table 4. Clinical management practices regarding diagnostic techniques and record-keeping of members of ORC-NZ $(\mathrm{n}=253)$ and ORION $(\mathrm{n}=992)$.

Future directions. Both ORC-NZ and ORION have been established in line with the common characteristics of PBRNs ${ }^{26}$. As such, each PBRN (both independently and when considered in combination) holds much potential to significantly advance the evidence-base and research capacity of and within osteopathy on a global scale. Many PBRNs (across many professions/areas of health care practice and geographical locations) draw upon 'big data' study designs (registry model) - whereby initial data collection is focused on establishing a centralized, coordinated patient record management system ${ }^{31}$ - limiting the ability to develop further projects sensitive to different clinical settings/circumstances or the evolving needs of grass-roots practitioners and the wider profession $^{32-34}$. In contrast, for both the ORION and ORC-NZ PBRN a sub-study model was employed - a design successfully founded and employed in other Australian PBRNs ${ }^{29,30}$. This approach to PBRN design - whereby initial data collection is focused exclusively on practitioner-relevant information collected via self-report aimed at establishing a practitioner PBRN database - facilitates the conduct of further nested studies addressing a variety of research questions and potentially utilising diverse research designs. Both ORION and ORC-NZ PBRNs are actively open for sub-study submissions by any appropriately qualified research teams. Sub-study guidelines and application forms can be located via the official ORION and ORC-NZ PBRN websites (please see www. orion-arccim.com and www.orcnz-arccim.org for further details). In order to help encourage use of the two osteopathy PBRNs for sub-study recruitment, below we outline some examples (not exhaustive) of the types of research and research designs that may be employed through further empirical investigation nested within and/ or building upon the ORC-NZ and ORION PBRN programs.

Pragmatic clinical research. For clinical trials to be of greatest value to the osteopathic profession requires they be both rigorous and practice-relevant/informed ${ }^{35}$. Unfortunately, there are a number of challenges in conducting pragmatic trials not the least being access to both clinics and clinicians ${ }^{36}$. The ORION and ORC-NZ PBRNs have the potential to facilitate impressive researcher access to both osteopathy clinics and individual osteopaths who may be interested in assisting with a pragmatic clinical trial study. As such, each of the two osteopathy PBRNs offer the osteopathic research community a welcome opportunity to advance beyond single-setting study designs which have to date tended to dominate clinical research in osteopathy ${ }^{37}$. Multi-centre clinical trials are well-regarded as they provide additional rigour to the study design, produce increased sensitivity of data regarding effect size, and may compensate for issues regarding clinician blinding ${ }^{38}$. It is also recommended that clinicians delay integrating new practices into their clinical decision-making until there is evidence drawn from multi-centre clinical trials to support the practice ${ }^{38,39}$. The shared characteristics of ORION and ORC-NZ add further strength to any potential clinical trial research using these PBRNs as they can support pragmatic multi-centre trials conducted in more than one country, thereby adding to the external validity of any findings.

Observational research. The ORION and ORC-NZ PBRNs can accommodate retrospective, prospective or cross-sectional observational sub-studies targeting osteopaths or their patients. Due to the substantive number of members in the two PBRNs, the total volume of patients accessible via the networks is considerable and presents the potential for statistically powerful sub-studies, with large samples of participants, to be recruited over a relatively short timeframe. Furthermore, sub-study researchers looking to recruit via one or both of the osteopathy PBRNs are able to employ study designs which rely upon successful recruitment of only a small number of patients per site across a large number of PBRN member sites, thereby not only reaching a statistically powerful sample size with ease but also maximising the generalisability of the data ${ }^{40}$. Researchers may also choose to use ORC-NZ or ORION to sample osteopaths as participants to explore clinical observations, attitudes and beliefs. 


\begin{tabular}{|c|c|c|c|c|c|c|c|c|}
\hline & \multicolumn{4}{|c|}{ ORC-NZ $(n=253)$} & \multicolumn{4}{|c|}{ ORION $(n=992)$} \\
\hline & Often & Sometimes & Rarely & Never & Often & Sometimes & Rarely & Never \\
\hline & $\mathbf{n}(\%)$ & n (\%) & $\mathbf{n}(\%)$ & n (\%) & $\mathbf{n}(\%)$ & n (\%) & $\mathbf{n}(\%)$ & $\mathbf{n}(\%)$ \\
\hline \multicolumn{9}{|l|}{ Conditions treated } \\
\hline Neck pain & $249(98.4)$ & $4(1.6)$ & $0(0.0)$ & $0(0.0)$ & $971(98.0)$ & $20(2.0)$ & $0(0.0)$ & $0(0.0)$ \\
\hline Thoracic spine and rib pain & $225(88.9)$ & $27(10.7)$ & $1(0.4)$ & $0(0.0)$ & $909(91.7)$ & $80(8.1)$ & $2(0.2)$ & $0(0.0)$ \\
\hline Low back pain & $249(98.4)$ & $4(1.6)$ & $0(0.0)$ & $0(0.0)$ & $977(98.7)$ & $10(1.0)$ & $1(0.1)$ & $2(0.2)$ \\
\hline Hip pain & $173(68.4)$ & $76(30.0)$ & $3(1.2)$ & $1(0.4)$ & $744(75.2)$ & $236(23.8)$ & $8(0.8)$ & $2(0.2)$ \\
\hline Knee musculoskeletal disorders & $126(49.8)$ & $116(45.9)$ & $11(4.4)$ & $0(0.0)$ & $491(49.7)$ & $456(46.2)$ & $38(3.9)$ & $3(0.3)$ \\
\hline Ankle musculoskeletal disorders & $97(38.3)$ & $120(47.4)$ & $36(14.0)$ & $0(0.0)$ & $333(33.7)$ & $501(50.7)$ & $150(15.2)$ & $5(0.5)$ \\
\hline Foot musculoskeletal disorders & $74(29.3)$ & $119(47.0)$ & $60(23.7)$ & $0(0.0)$ & $294(29.7)$ & $484(48.9)$ & $207(20.9)$ & $5(0.5)$ \\
\hline Shoulder musculoskeletal disorders & $207(81.8)$ & $45(17.8)$ & $1(0.4)$ & $0(0.0)$ & $801(81.0)$ & $176(17.8)$ & $10(1.0)$ & $2(0.2)$ \\
\hline Elbow musculoskeletal disorders & $60(23.8)$ & $140(55.6)$ & $49(19.4)$ & $3(1.2)$ & $251(25.5)$ & $558(56.6)$ & $170(17.2)$ & $7(0.7)$ \\
\hline Wrist musculoskeletal disorders & $45(17.9)$ & $126(50.2)$ & $79(31.5)$ & $1(0.4)$ & $188(19.0)$ & $469(47.4)$ & $325(32.9)$ & $7(0.7)$ \\
\hline Hand musculoskeletal disorders & $33(13.2)$ & $100(39.8)$ & $114(45.4)$ & $4(1.6)$ & $121(12.3)$ & $352(35.7)$ & $482(48.9)$ & $30(3.1)$ \\
\hline Postural disorders & $132(52.6)$ & $89(35.5)$ & $30(12.0)$ & $0(0.0)$ & $675(68.3)$ & $261(26.4)$ & $52(5.3)$ & $1(0.1)$ \\
\hline Degenerative spine disorders & $123(49.0)$ & $95(37.9)$ & $31(12.4)$ & $2(0.8)$ & $599(60.6)$ & $324(32.8)$ & $66(6.7)$ & $0(0.0)$ \\
\hline Headache disorders & $219(86.6)$ & $33(13.0)$ & $1(0.4)$ & $0(0.0)$ & $892(90.1)$ & $95(9.6)$ & $2(0.2)$ & $1(0.1)$ \\
\hline Migraine disorders & $104(41.1)$ & $126(49.8)$ & $22(8.7)$ & $1(0.4)$ & $400(40.5)$ & $518(52.4)$ & $69(7.0)$ & $1(0.1)$ \\
\hline Spinal health maintenance & $121(48.0)$ & $98(38.9)$ & $31(12.3)$ & $2(0.8)$ & $458(46.4)$ & $378(38.3)$ & $136(13.8)$ & $16(1.6)$ \\
\hline Chronic or persistent pain & $127(50.2)$ & $108(42.7)$ & $18(7.1)$ & $0(0.0)$ & $630(63.7)$ & $310(31.3)$ & $47(4.8)$ & $2(0.2)$ \\
\hline Tendinopathies & $76(30.2)$ & $129(51.2)$ & $44(17.5)$ & $3(1.2)$ & $410(41.5)$ & $477(48.2)$ & $96(9.7)$ & $6(0.6)$ \\
\hline Temporomandibular joint (TMJ) disorders & $35(13.8)$ & $116(45.9)$ & $98(38.7)$ & $4(1.6)$ & $183(18.5)$ & $504(51.0)$ & $291(29.5)$ & $10(1.0)$ \\
\hline Non-musculoskeletal disorders & $41(16.3)$ & $92(36.5)$ & 77 (30.6) & $42(16.7)$ & $126(12.9)$ & $262(26.7)$ & $318(32.5)$ & $274(28.0)$ \\
\hline \multicolumn{9}{|l|}{ Populations treated } \\
\hline Children (up to 3 years) & $72(28.8)$ & $76(30.4)$ & $51(20.4)$ & $51(20.4)$ & $156(15.8)$ & $217(22.0)$ & $304(30.8)$ & $311(31.5)$ \\
\hline Children (4 to 18 years) & $89(35.3)$ & $129(51.2)$ & $33(13.1)$ & $1(0.4)$ & $270(27.3)$ & $545(55.0)$ & $168(17.0)$ & $8(0.8)$ \\
\hline Older people (65 year or over) & $168(66.4)$ & $81(32.0)$ & $4(1.6)$ & $0(0.0)$ & $572(57.7)$ & $369(37.2)$ & $48(4.8)$ & $2(0.2)$ \\
\hline Maori/Australian Indigenous* & $39(15.4)$ & $141(55.7)$ & $71(28.0)$ & $2(0.8)$ & $7(0.7)$ & $105(10.6)$ & $547(55.3)$ & $331(33.4)$ \\
\hline Pregnant women & $75(29.6)$ & $134(53.0)$ & $43(17.0)$ & $1(0.4)$ & $344(34.7)$ & $534(53.9)$ & $108(10.9)$ & $5(0.5)$ \\
\hline People with sports-related injuries & $131(51.8)$ & $104(41.1)$ & $18(7.1)$ & $0(0.0)$ & $501(50.6)$ & $432(43.6)$ & $53(5.4)$ & $4(0.4)$ \\
\hline People with work-related injuries & $164(64.8)$ & $81(32.0)$ & $8(3.2)$ & $0(0.0)$ & - & - & - & - \\
\hline People with traffic-related injuries & $68(26.9)$ & $136(53.8)$ & $45(17.8)$ & $4(1.6)$ & - & - & - & - \\
\hline People receiving post-surgical rehabilitation & $35(13.8)$ & $125(49.4)$ & $84(34.3)$ & $6(2.4)$ & $79(8.0)$ & $456(46.1)$ & $396(40.0)$ & $58(5.9)$ \\
\hline Non-English speaking ethnic groups & $12(4.8)$ & $60(23.8)$ & $105(41.7)$ & $75(29.8)$ & $33(3.3)$ & $153(15.5)$ & $457(46.2)$ & $346(35.0)$ \\
\hline Treat patients with ACC reimbursement & $223(88.1)$ & $23(9.1)$ & $0(0.0)$ & $7(2.8)$ & - & - & - & - \\
\hline
\end{tabular}

Table 5. Conditions and populations treated by members of ORC-NZ $(\mathrm{n}=253)$ and ORION $(\mathrm{n}=992)$. *Data reports treatment of Maori populations for ORC-NZ and Australian indigenous populations for ORION.

Findings from such studies can be used to: inform the development of clinical trials; identify knowledge or skill gaps that may benefit from knowledge translation interventions; and mobilise knowledge developed through clinical experience which may assist with the understanding and management of conditions commonly seen within osteopathic practice ${ }^{41,42}$.

Qualitative research. The sub-study design of both ORC-NZ and ORION affords the flexibility to accommodate research projects employing qualitative research methods. One of the distinguishing features of qualitative research is the preference for investigating naturally occurring behaviour and settings or at least the direct accounts of participants involved in such naturally occurring settings ${ }^{43}$. This feature of qualitative research is particularly well supported by the two osteopathy PBRNs given they are characterised by a focus upon grass-roots providers delivering care to the community from clinical practices. Researchers can use ORION and ORC-NZ to explore, through qualitative research fieldwork, a deeper understanding of the meanings and experiences of osteopaths and their patients (plus other related stakeholders as necessary) with regards to a wide range of pertinent topics ${ }^{44}$.

Accumulation of case reports and single-subject research. Case reports can be described as a form of descriptive research that seeks to identify explanatory patterns for phenomena ${ }^{45}$. Data captured from individual clinical cases through case reports can form the basis of new directions in clinical research ${ }^{46}$. Case reports can be undertaken as prospective case series through which a researcher can work with osteopaths with a special interest in the management of a particular condition or in the application of a specific osteopathic technique. Data for a case series can be collected retrospectively by osteopaths using data extraction tables provided by a research team to help 


\begin{tabular}{|c|c|c|c|c|c|c|c|c|}
\hline & \multicolumn{4}{|c|}{ ORC-NZ (n=253) } & \multicolumn{4}{|c|}{ ORION $(n=992)$} \\
\hline & Often & Sometimes & Rarely & Never & Often & Sometimes & Rarely & Never \\
\hline \multicolumn{9}{|l|}{ Topics discussed with patients } \\
\hline Diet/Nutrition & $104(41.3)$ & $118(46.8)$ & $29(11.5)$ & $1(0.4)$ & 375 (37.9) & $465(47.0)$ & $142(14.3)$ & $8(0.8)$ \\
\hline Smoking/Drugs/Alcohol & $32(12.8)$ & $132(52.8)$ & $80(32.0)$ & $6(2.4)$ & $179(18.1)$ & $454(45.9)$ & $324(32.7)$ & $33(3.3)$ \\
\hline Physical activity/fitness & $219(86.9)$ & $29(11.5)$ & $4(1.6)$ & $0(0.0)$ & $886(89.4)$ & $99(10.0)$ & $6(0.6)$ & $0(0.0)$ \\
\hline Occupational health and safety & $109(43.3)$ & $101(40.1)$ & $36(14.3)$ & $6(2.4)$ & $506(51.2)$ & $374(37.8)$ & $95(9.6)$ & $14(1.4)$ \\
\hline Pain counselling & $55(22.0)$ & $106(42.4)$ & $79(31.6)$ & $10(4.0)$ & $264(26.6)$ & $411(41.5)$ & $266(26.8)$ & $50(5.1)$ \\
\hline Stress management & $141(53.8)$ & $103(39.3)$ & $18(6.9)$ & $0(0.0)$ & $489(49.4)$ & $410(41.5)$ & $85(8.6)$ & $5(0.5)$ \\
\hline Nutritional supplements & $66(26.3)$ & $119(47.4)$ & $52(20.7)$ & $14(5.6)$ & $252(25.4)$ & $446(45.0)$ & $247(24.9)$ & $46(4.6)$ \\
\hline Medications (including for pain/inflammation) & $92(36.4)$ & $131(51.8)$ & $22(8.7)$ & $8(3.2)$ & $391(39.5)$ & $475(48.0)$ & $115(11.6)$ & $9(0.9)$ \\
\hline \multicolumn{9}{|l|}{ Treatment techniques used } \\
\hline Strain/Counterstrain & $66(26.9)$ & $76(31.0)$ & $61(24.9)$ & $42(17.1)$ & $420(42.4)$ & $324(32.7)$ & $180(18.2)$ & $66(6.7)$ \\
\hline Muscle energy techniques & $151(59.9)$ & $68(26.9)$ & $24(9.5)$ & $9(3.6)$ & $788(79.5)$ & $154(15.5)$ & $34(3.4)$ & $15(1.5)$ \\
\hline High velocity low amplitude/spinal manipulation & $155(61.3)$ & $45(17.8)$ & $30(11.9)$ & $23(9.1)$ & $632(63.8)$ & $231(23.3)$ & $86(8.7)$ & $42(4.2)$ \\
\hline Peripheral joint manipulation & $136(53.8)$ & $72(28.5)$ & $31(12.3)$ & $14(5.5)$ & $393(39.7)$ & $347(35.1)$ & $212(21.4)$ & $37(3.7)$ \\
\hline Soft tissue techniques & $221(87.4)$ & $15(5.9)$ & $11(4.4)$ & $6(2.4)$ & $848(85.7)$ & $85(8.6)$ & $46(4.7)$ & $11(1.1)$ \\
\hline Myofascial release & $154(60.9)$ & $62(24.5)$ & $23(9.1)$ & $14(5.5)$ & $612(61.8)$ & $266(26.9)$ & $79(8.0)$ & $33(3.3)$ \\
\hline Cranial techniques & $128(50.6)$ & $68(26.9)$ & $31(12.3)$ & $26(10.3)$ & $233(23.5)$ & $219(22.1)$ & $213(21.5)$ & $325(32.8)$ \\
\hline Facilitated positional release & $62(24.8)$ & $78(31.2)$ & 49 (19.6) & $61(24.4)$ & $166(16.8)$ & $298(30.1)$ & $314(31.8)$ & $211(21.3)$ \\
\hline Needling techniques & $12(4.7)$ & $4(1.6)$ & $4(1.6)$ & $233(92.1)$ & $234(23.6)$ & $165(16.7)$ & $51(5.2)$ & $540(54.6)$ \\
\hline Visceral techniques & $58(22.9)$ & $98(38.7)$ & $69(27.3)$ & $28(11.1)$ & $98(70.0)$ & $272(27.5)$ & $411(41.5)$ & $210(21.2)$ \\
\hline Lymphatic pump & $24(9.5)$ & $93(36.8)$ & $97(38.3)$ & $39(15.4)$ & $84(8.5)$ & $316(31.9)$ & 415 (41.9) & $176(17.8)$ \\
\hline Autonomic balancing & $52(20.8)$ & 59 (23.6) & $59(23.6)$ & $80(32.0)$ & $157(15.9)$ & $190(19.2)$ & $216(21.8)$ & $427(43.1)$ \\
\hline Biodynamic techniques & 49 (19.4) & $34(13.5)$ & $47(18.7)$ & $122(48.4)$ & $155(15.6)$ & $94(9.5)$ & $156(15.7)$ & $586(59.1)$ \\
\hline Functional techniques & $115(45.5)$ & $85(33.6)$ & $42(16.6)$ & $11(4.4)$ & $270(27.3)$ & $335(33.8)$ & $251(25.3)$ & $135(13.6)$ \\
\hline $\begin{array}{l}\text { Balanced ligamentous tension/Ligamentous } \\
\text { articular strain }\end{array}$ & $120(47.8)$ & 67 (26.7) & 46 (18.3) & $18(7.2)$ & $349(35.2)$ & $279(28.2)$ & $213(21.5)$ & $150(15.1)$ \\
\hline Exercise prescription or advice & $198(78.3)$ & $46(18.2)$ & $8(3.2)$ & $1(0.4)$ & $733(74.0)$ & $218(22.0)$ & $35(3.5)$ & $4(0.4)$ \\
\hline Chapmans reflexes & $10(4.0)$ & $18(7.2)$ & $54(21.5)$ & $169(67.3)$ & $24(2.4)$ & $78(7.9)$ & $190(19.2)$ & $698(70.5)$ \\
\hline Shockwave therapy & $2(0.8)$ & $6(2.4)$ & $2(0.8)$ & $242(96.0)$ & $18(1.8)$ & $35(3.5)$ & $27(2.7)$ & $910(91.9)$ \\
\hline Ultrasound therapy & $1(0.4)$ & $3(1.2)$ & $3(1.2)$ & $245(97.2)$ & $27(2.7)$ & $32(3.2)$ & $50(5.1)$ & $880(89.0)$ \\
\hline TENS or other electrotherapy & $6(2.4)$ & $3(1.2)$ & $6(2.4)$ & $234(94.0)$ & $19(1.9)$ & $25(2.5)$ & $67(6.8)$ & $879(88.8)$ \\
\hline Instrument-assisted manipulative techniques & $0(0.0)$ & $2(0.8)$ & $3(1.2)$ & $247(98.0)$ & $2(0.2)$ & $11(1.1)$ & $20(2.0)$ & $956(96.7)$ \\
\hline Instrument-assisted soft tissue mobilisation & $2(0.8)$ & $7(2.8)$ & $9(3.6)$ & $234(92.9)$ & $12(1.2)$ & $29(2.9)$ & $37(3.7)$ & $912(92.1)$ \\
\hline Trigger point therapy & $73(29.1)$ & $75(30.0)$ & $43(17.1)$ & 60 (23.9) & $258(26.1)$ & $353(35.7)$ & 184 (18.6) & $195(19.7)$ \\
\hline Sports taping & $25(9.9)$ & 57 (22.6) & $85(33.7)$ & $85(33.7)$ & $122(12.3)$ & $330(33.3)$ & $311(31.4)$ & $227(22.9)$ \\
\hline Breathing retraining & $63(25.2)$ & $108(43.2)$ & $54(21.6)$ & $25(10.0)$ & - & - & - & - \\
\hline
\end{tabular}

Table 6. Features of the clinical treatments and care plans of members of ORC-NZ $(n=253)$ and ORION $(\mathrm{n}=992)$.

summarise information of existing case records ${ }^{46}$. In contrast to case reports, single subject research, including $\mathrm{N}$ of 1 trials, are characterised by repeated measures of an observable and clinically-relevant target behaviour throughout at least one pre-treatment (baseline) and intervention phase ${ }^{45}$. While the PBRN infrastructure of ORION and ORC-NZ is not a requirement for either case reports or single-subject research, these networks do nevertheless offer researchers the ability to collect case series and multi-person $\mathrm{N}$ of 1 studies more easily and with less burden on individual clinicians. This is particularly the case for rarely treated conditions (e.g. hand disorders), specific populations (e.g. non-English speaking ethnic groups) or specialised treatments (e.g Chapmans reflexes, needling techniques or visceral techniques) whereby researchers may be able to more effectively identify relevant cases for inclusion in their study. Furthermore, inviting osteopaths from multiple sites to share case reports and assist with data collection for single-subject research can strengthen the rigour of the data and robustness of the findings ${ }^{46,47}$.

\section{Conclusions}

Both ORION and ORC-NZ PBRNs are powerful and innovative resources that will help advance osteopathy research in Australia and New Zealand as well as help facilitate collaborations with interested practitioners and researchers further afield. When combined, these two osteopathy PBRNs represent the largest coverage of any health profession within any existing voluntary PBRN and as such signify a substantial opportunity for osteopathy and osteopathy researchers. Nevertheless, it remains that these innovative resources require extensive engagement from practitioners, professional associations, methodologists and others in order to realise their 
full potential and there are always challenges in engaging large numbers of clinicians in the research process over time. However, given the initial support and investment of both Osteopathy Australia and Osteopaths New Zealand and the impressive response of so many osteopaths across both Australia and New Zealand to the initial calls for PBRN participation, there is reason to remain optimistic that both ORION and ORC-NZ can help grow osteopathy research and help advance a research culture that is rigorous, clinically relevant and reflects the diversity and nature of osteopathic practice across Australasia.

Received: 20 August 2019; Accepted: 17 December 2019; Published online: 21 January 2020

\section{References}

1. Osteopathic International Alliance (2013).

2. Steel, A. et al. Complementary medicine use in the Australian population: Results of a nationally-representative cross-sectional survey. Scientific Reports, In press (2018).

3. Murthy, V. et al. Consultations with complementary and alternative medicine practitioners amongst wider care options for back pain: a study of a nationally representative sample of 1,310 Australian women aged 60-65 years. Clinical rheumatology 33, 253-262 (2014).

4. Baer, H. A. Osteopathy in Australasia: From marginality to a fully professionalised system of health care. International Journal of Osteopathic Medicine 12, 25-31, https://doi.org/10.1016/j.ijosm.2008.05.002 (2009).

5. Australian Government. In C2019C00116 (ed Australian Government) (Federal Register of Legislation, Canberra, Australia, 2019).

6. Australasian Osteopathic Accreditation Council. About Us, https://osteopathiccouncil.org.au/about-us/ (2018).

7. Steel, A., Blaich, R., Sundberg, T. \& Adams, J. The role of osteopathy in clinical care: broadening the evidence-base. International Journal of Osteopathic Medicine 24, 32-36 (2017).

8. Franke, H., Franke, J. D. \& Fryer, G. Osteopathic manipulative treatment for nonspecific low back pain: A systematic review and meta-analysis. BMC Musculoskeletal Disorders 15, https://doi.org/10.1186/1471-2474-15-286 (2014).

9. Orrock, P. J. \& Myers, S. P. Osteopathic intervention in chronic non-specific low back pain: a systematic review. BMC Musculoskelet Disord 14, 129, https://doi.org/10.1186/1471-2474-14-129 (2013).

10. Licciardone, J. C., Brimhall, A. K. \& King, L. N. Osteopathic manipulative treatment for low back pain: a systematic review and meta-analysis of randomized controlled trials. BMC Musculoskeletal Disorders 6, 1-12, https://doi.org/10.1186/1471-2474-6-43 (2005).

11. Chown, M. et al. A prospective study of patients with chronic back pain randomised to group exercise, physiotherapy or osteopathy. Physiotherapy 94, 21-28, https://doi.org/10.1016/j.physio.2007.04.014 (2008).

12. MacDonald, R. S., Mro, M. \& Bell, C. J. An open controlled assessment of osteopathic manipulation in nonspecific low-back pain. Spine 15, 364-370 (1990)

13. Williams, N. H. et al. Randomized osteopathic manipulation study (ROMANS): pragmatic trial for spinal pain in primary care. Family Practice 20, 662-669, https://doi.org/10.1093/fampra/cmg607 (2003).

14. Licciardone, J. C., Kearns, C. M. \& Minotti, D. E. Outcomes of osteopathic manual treatment for chronic low back pain according to baseline pain severity: Results from the OSTEOPATHIC Trial. Manual Therapy 18, 533-540, https://doi.org/10.1016/j. math.2013.05.006 (2013)

15. Anderson, R. E. \& Seniscal, C. A comparison of selected osteopathic treatment and relaxation for tension-type headaches. Headache: The Journal of Head \& Face Pain 46, 1273-1280 (2006)

16. Schabert, E. \& Crow, W. T. Impact of osteopathic manipulative treatment on cost of care for patients with migraine headache: a retrospective review of patient records. J Am Osteopath Assoc. 109, 403-407 (2009).

17. Schwerla, F., Rother, K., Rother, D., Ruetz, M. \& Resch, K.-L. Osteopathic Manipulative Therapy in Women With Postpartum Low Back Pain and Disability: A Pragmatic Randomized Controlled Trial. The Journal 115, 416 (2015).

18. Licciardone, J. C. et al. Osteopathic manipulative treatment of back pain and related symptoms during pregnancy: a randomized controlled trial. Am J Obstet Gynecol 202(43), e41-48, https://doi.org/10.1016/j.ajog.2009.07.057 (2010).

19. Posadzki, P., Myeong Soo, L. \& Ernst, E. Osteopathic Manipulative Treatment for Pediatric Conditions: A Systematic Review. Pediatrics 132, 140-152, https://doi.org/10.1542/peds.2012-3959 (2013).

20. Adams, J., Steel, A., Moore, C., Amorin-Woods, L. \& Sibbritt, D. Establishing the ACORN national practitioner database: strategies to recruit practitioners to a national Practice-Based Research Network. Journal of Manipulative and Physiological Therapeutics 39, 594-602 (2016)

21. Szmelskyj, A. O. The difference between holistic osteopathic practice and manipulation. J Interprof Care 5, 67-79 (1990).

22. Wardle, J., Steel, A., Casteleijn, D. \& Bowman, D. An evidence-based overview of naturopathic practice in Australia. Australian Journal of Herbal and Naturopathic Medicine 31, 9 (2019).

23. Adams, J. et al. In Traditional, Complementary and Integrative Medicine: An international reader (eds J Adams et al.) Ch. 31, 275-282 (Palgrave Macmillan, 2012).

24. Lindbloom, E. J., Ewigman, B. G. \& Hickner, J. M. Practice-based research networks: the laboratories of primary care research. Medical care 42, III-45-III-49 (2004).

25. Thomas, P., Griffiths, F., Kai, J. \& O’Dwyer, A. Networks for research in primary health care. Bmj. 322, 588-590 (2001).

26. Davis, M. M., Keller, S., DeVoe, J. E. \& Cohen, D. J. Characteristics and lessons learned from practice-based research networks (PBRNs) in the United States. Journal of Healthcare Leadership 4, 107-116 (2012).

27. Graham, D. G. et al. Strategies for planning and launching PBRN research studies: a project of the Academy of Family Physicians National Research Network (AAFP NRN). The Journal of the American Board of Family Medicine 20, 220-228 (2007).

28. Lee, H. et al. Complementary and alternative medicine research in practice-based research networks: A critical review. Complementary therapies in medicine (2019).

29. Adams, J. et al. A cross-sectional examination of the profile of chiropractors recruited to the Australian Chiropractic Research Network (ACORN): a sustainable resource for future chiropractic research. BMJ Open 7, e015830 (2017).

30. Steel, A. et al. An overview of the Practitioner Research and Collaboration Initiative (PRACI): a practice-based research network for complementary medicine. BMC Complementary and Alternative Medicine 17, 87 (2017).

31. Steel, A., Frawley, J., Sibbritt, D., Broom, A. \& Adams, J. The characteristics of women who use hypnotherapy for intrapartum pain management: preliminary insights from a nationally-representative sample of Australian women. Complementary Therapies in Medicine 25, 67-70 (2016).

32. Reid, R. \& Steel, A. The importance of the PRACI project for grass roots complementary medicine practice: a call for practitioner involvement. Australian. Journal of Herbal Medicine 27, 101+ (2015).

33. Steel, A., Adams, J. \& Sibbritt, D. Developing a multi-modality complementary medicine practice-based research network: the PRACI project. Advances in Integrative Medicine 1, 113-118 (2014). 
34. Adams, J., Steel, A., Chang, S. \& Sibbritt, D. Helping address the national research and research capacity needs of Australian chiropractic: introducing the Australian Chiropractic Research Network (ACORN) project. Chiropractic \& Manual Therapies 23, 12 (2015).

35. Merali, Z. \& Wilson, J. R. Explanatory versus pragmatic trials: An essential concept in study design and interpretation. Clinical spine surgery 30, 404-406 (2017).

36. Califf, R. M. \& Sugarman, J. Exploring the ethical and regulatory issues in pragmatic clinical trials. Clinical Trials 12, 436-441 (2015).

37. Licciardone, J. C., Minotti, D. E., Gatchel, R. J., Kearns, C. M. \& Singh, K. P. Osteopathic manual treatment and ultrasound therapy for chronic low back pain: a randomized controlled trial. The Annals of Family Medicine 11, 122-129 (2013).

38. Bellomo, R., Warrillow, S. J. \& Reade, M. C. Why we should be wary of single-center trials. Critical care medicine 37, 3114-3119 (2009).

39. Chung, K. C. \& Song, J. W., group, W. s. A Guide on Organizing a Multicenter Clinical Trial: the WRIST study group. Plastic and reconstructive surgery 126, 515-523, https://doi.org/10.1097/PRS.0b013e3181df64fa (2010).

40. Delgado-Rodriguez, M. \& Llorca, J. Bias. Journal of epidemiology and community health 58, 635-641 (2004).

41. Leech, B., Schloss, J. \& Steel, A. Health services research as a framework for expanding a whole systems research agenda in complementary and integrative medicine: the example of intestinal permeability. European Journal of Integrative Medicine 17, 22-25 (2018).

42. Adams, J., Steel, A. \& Reid, R. In Public Health and Health Services Research in Traditional, Complementary and Integrative Health Care: International Perspectives (eds. Adams J. et al.) (World Scientific, 2019).

43. Pope, C. \& Mays, N. Qualitative research in health care. (John Wiley \& Sons, 2013).

44. Pope, C. \& Mays, N. Reaching the parts other methods cannot reach: an introduction to qualitative methods in health and health services research. BMJ: British Medical Journal 311, 42 (1995).

45. Backman, C. L. \& Harris, S. R. Case Studies, Single-Subject Research, and N of 1 Randomized Trials: Comparisons and Contrasts1. American Journal of Physical Medicine \& Rehabilitation 78, 170-176 (1999).

46. Fogarty, S. \& Wardle, J. Integrative medicine case series: a clinician's guide to publication. Advances in Integrative Medicine 2, 147-151 (2015).

47. Raman, G. et al. Evaluation of person-level heterogeneity of treatment effects in published multiperson N-of-1 studies: systematic review and reanalysis. BMJ Open 8, e017641, https://doi.org/10.1136/bmjopen-2017-017641 (2018).

\section{Acknowledgements}

The Osteopathy Research and Innovation Network (ORION) was established through funding provided by Osteopathy Australia. The Osteopathy Research Connect New Zealand (ORC-NZ) was established through funded provided by Osteopaths New Zealand.

\section{Author contributions}

J.A., D.S. and A.S. conceived of the practice-based research networks. A.S. and W.P. prepared the tables. A.S. and J.A. wrote the manuscript. All authors reviewed the manuscript.

\section{Competing interests}

The authors declare no competing interests.

\section{Additional information}

Correspondence and requests for materials should be addressed to A.S.

Reprints and permissions information is available at www.nature.com/reprints.

Publisher's note Springer Nature remains neutral with regard to jurisdictional claims in published maps and institutional affiliations.

(c) (i) Open Access This article is licensed under a Creative Commons Attribution 4.0 International

License, which permits use, sharing, adaptation, distribution and reproduction in any medium or format, as long as you give appropriate credit to the original author(s) and the source, provide a link to the Creative Commons license, and indicate if changes were made. The images or other third party material in this article are included in the article's Creative Commons license, unless indicated otherwise in a credit line to the material. If material is not included in the article's Creative Commons license and your intended use is not permitted by statutory regulation or exceeds the permitted use, you will need to obtain permission directly from the copyright holder. To view a copy of this license, visit http://creativecommons.org/licenses/by/4.0/.

(C) The Author(s) 2020 